\title{
Proposing a Framework for Developing Supply Chains of Medical Devices
}

\author{
Kun Liao \\ Department of Finance and Supply Chain Management, College of Business, Central \\ Washington University, $2000068^{\text {th }}$ Ave W, Lynnwood WA 98036, USA \\ E-mail: liaok@cwu.edu (Corresponding Author)
}

\author{
Xiaodong Deng \\ Department of Decision and Information Sciences, School of Business Administration, Oakland \\ University, Rochester, MI 48309-4493, USA \\ E-mail: deng@oakland.edu
}

Yan (Grace) Wang

Starbucks Corporation, USA

E-mail: wangyangrace@gmail.com

\author{
Ozden Bayazit \\ Department of Finance and Supply Chain Management, College of Business, Central \\ Washington University, 20000 68th Avenue W, Lynnwood, WA 98036, USA \\ Email: bayazito@cwu.edu
}

\begin{abstract}
To help develop supply chains for a medical device, this study proposed a framework based on literature review and the unique characteristics of medical devices. The framework first evaluates the structure of the medical device, the suppliers of raw materials or components, and the emerging technologies and manufacturing processes to be used to build the device. It then assesses the quality regulations and standards for the device and the manufacturing processes, the location of the suppliers, and the operation and maintenance of the device along the supply chain. This framework was applied to a case where supply chains were developed through Porter's cluster mapping technique for two medical devices: an ultrasound machine and a prosthetic ankle. The preliminary results suggested that the features of the medical devices influenced the choice of their supply chains. In particular, a research-oriented device with customized components should have a localized supply chain (e.g., within Washington State in this case) while the consumer-oriented device with standardized components could have a national or even a global supply chain. Future research directions are suggested.
\end{abstract}

Keywords: medical devices, supply chain, design, cluster, Washington State, U.S.

\section{INTRODUCTION}

Supply chains for medical devices have a unique and complex structure that is governed by many standards and regulations and depends heavily on trust (Cheng-Min et al., 2013). Many healthcare institutions are now assessing innovative ideas for optimizing their medical device supply chains (Unger and Landis, 2016). Different devices may use different types of advanced technologies to enhance product functionalities. For example, an ultrasound machine may employ electronic technologies while prosthetic ankle may rely on traditional machinery technologies. What is unique is that all supply chains of medical devices need Food and Drug Administration (FDA) approval, ISO and clean room certifications.

The goal of this research is to propose a framework for the development of a medical device supply chain centered on the Great Seattle area in Washington State - a state that is considered as a major medical device cluster in the United States. The research explores how the features of a medical device impact on the choice of its supply chain. While a typical supply chain includes manufacturers, parts suppliers, raw material suppliers, and distribution channels, the focus of this study will be on the supply chain segment that contains manufacturers and the suppliers of both the raw materials and the parts.

The organization of the remaining portions is as follows. Section 2 reviews related literature and introduce the framework and its components identified from pieces of literature or interviews. Section 3 reports a case study with supply chains for two typical medical devices (e.g., an ultrasound machine and a prosthetic ankle). Section 4 discusses the case results and suggests future research directions.

\section{LITERATURE REVIEW, THE FRAMEWORK, AND ITS COMPONENTS}

The focuses of the studies related to medical device supply chain are diverse and largely on the assessment of the supply chain network in general or on the management of supply chain activities. In particular, some explored analytical models for the profit, location-allocation, or environmental and social impacts of business activities of the 
supply chain or supply chain network. Based on the largest manufacturer of medical devices in the middle east region, Hasani et al. (2015) proposed an optimization model to maximize the after-tax profit of a closed-loop global supply chain network (GSCN) for medical devices under budget uncertainty. Zarrinpoor et al. (2018) suggested a hierarchical location-allocation model address a health service network design problem by considering referral structure, demand uncertainty, service and geographical accessibility, patients in urgency or treatment strategies, service quality levels, and risk of unexpected disruptive events. In trying to address the concern about environmental and social impacts of business activities by offering decision making and planning tools or techniques, Pishvaee et al. (2014) examined a multiobjective possibilistic programming model to design a sustainable medical supply chain network under uncertainty considering conflicting economic, environmental and social objectives.

Others explored the process control of, the adoption and use of information technology for, or the user participation in the supply chain activities. Castiaux (2010; 2011) emphasized the importance of control of supply chain of pharmaceutical and medical device manufacturing, as temperature-sensitive products are increasing and they must be kept within a specific temperature range during storage and transportation. The suggested approach includes developing written procedures, validating shipping, evaluating transportation and storage locations, monitoring temperature during shipping, and training personnel. Kumar et al. (2008) examined the impact of packaging design on purchasing decisions in hospitals. While the literature suggested an association between packaging design and an efficient inventory management program, the results from a small number of participating community hospitals in the USA suggested that the hospitals' purchasing decisions were not related to the packaging design and environment-friendly suppliers or medical products. Xie et al. (2016) explored the adoption and use of information and communication technology (ICT) in managing medical devices in the reverse exchange (RE) systems where devices were returned to the source for an exchange. They found that the adoption and integration of ICT into key operational processes increase with the perceived risks and value associated with medical devices. Unger and Landis (2016) used life cycle assessment
(LCA) and life cycle cost assessment (LCCA) to model the environmental and economic impacts of medical device supply chains when different levels of reprocessed medical devices were used at Phoenix Baptist Hospital (PBH) in Phoenix, Arizona to alleviate the burden from increasing healthcare costs and decreasing insurance reimbursements. The results suggested that when reprocessing inputs were minimized, employing reprocessing was favorable from both global warming and human health perspective. Grocott et al. (2007) observed that many medical devices were generated in isolation of the clinical users and thus vulnerable to failure during service. Therefore, they proposed a model for user involvement in medical device design and evaluation during product development and purchasing stages.

However, current literature on the supply chain development for medical devices is very limited. The focus of this type of research is on the upstream of the supply chain including the identification and selection of raw material providers and component manufacturers. A general framework that may provide guidance for developing supply chains of medical devices will be helpful, potentially, in reducing costs, promoting regulation compliance, using information technologies, or involving in end-users of the devices. Figure 1 presents a typical supply chain and the development framework for medical devices. The components are presented underneath the supply and the shading of each component indicates the scope to which the suggested component could be applied.

The first component is the medical devices and their bill of materials (BOM). The BOM of each device helps determine its components, sub-components, and the basic elements/parts. Once the BOM is developed, the raw materials of each part have to be determined, and the manufacturing process for each part and the assembly process of sub-components and components have to be designed. The second is the identification and selection of the suppliers of components, sub-components, and raw materials. The third is the quality regulations and standards for medical devices and their suppliers. The fourth component is the consideration of the emerging technologies that may be embedded in the devices or used to manufacture the devices. The fifth is the distribution and global markets of medical devices. The sixth is the maintenance, repair, and operations of medical device supply chains.

A Typical Supply Chain

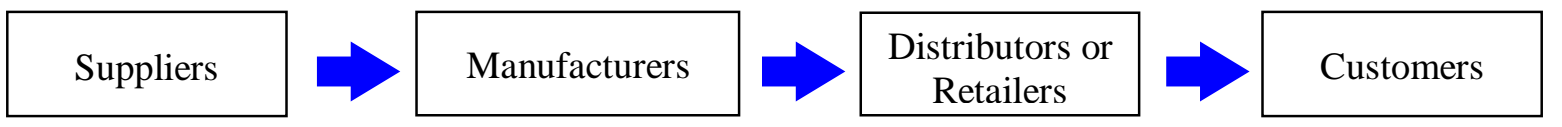

1. Developing Bill of Materials

2. Selecting Suppliers

3. Developing Quality Regulations and Standards

4. Including Emerging Technologies

5. Establishing Distributions and Global Network

6. Considering Supply Chain Maintenance, Repair, and Operations (MRO) 


\subsection{The Medical Devices and Their Bill of Material}

Before manufacturers look for suppliers and start the selection process, they need to have a more in-depth understanding of the device first. From the structure's perspective, manufacturers need to develop the bill of materials (BOM) for each device to be manufactured.

$\mathrm{A}$ BOM is a list of the components, sub-components, parts, raw materials, and the quantities of each needed to manufacture a device (Reid and Sanders, 2002). It is essentially "the skeleton for planning and scheduling almost all products" (Mather, 1986). The BOM elaborates the structural details of the device. These details provide a basis for identifying potential suppliers, designing the manufacturing process, and selecting raw materials and channels of transportation of each piece. They also help communication among different departments within a manufacturer or across manufacturing partners. Wells et al. (2011) suggest that when technological items are first introduced to the supply chain, they are expensive, but as the items become more readily available they become more cost-efficient. The BOM will help identify how many pieces are not readily available on the market and need to be developed or customized. If a piece is new or needs to be developed with new technology, the cost of manufacturing this piece will be more expensive, leading to a higher price of the device.

\subsection{Supplier Identification and Selection}

When manufacturers identify and select suppliers, the risk that the supplier fails to deliver critical parts is a major concern. While a backup facility could be built for the critical parts to address the risk (Ratick et al., 2008), cost incurs. The newer the technology is used to build the parts, the higher the risk and the cost are to maintain the backup facility. When a part is well established on the market, its risk and its cost are much lower (Ratick et al., 2008). Liao et al. (2014) present a model to determine if the risk of a critical part is large enough to justify the cost of having a back-up supplying facility.

Formby and Malhotra (2016) state that the risk of supply disruptions has increased significantly due to widely dispersed global supply chains. Ali and Nakade (2015) proposed an analytical framework of a multicommodity multi-stage supply chain considering disruptions risk at the distribution centers (DCs) and suppliers. They concluded that managing disruptions risk has become one of the most important concerns in the global marketplace. Wang et al. (2006) developed a measurement model as guidance for managing supply chain uncertainty and risk.

The device manufacturers or the OEMs (Original Equipment Manufacturers) should not be confused with an Own Brand Labeler (OBL). The latter refers to a private party who contracts with the OEM to sell one device under two different names (Emergo Group, 2007). The biggest difference between the OEM and the OBL is that, according to the European Commission (2007), if there are issues with a medical device, the OBL is held to the same standard as the OEM, and is just as liable to any issues. In this context, both OBL and OEM are considered to be the same, even if the OBL does not actually manufacture the device. In the United States, one of the largest agencies involved with OEMs is the Medical Device Manufacturers Association (MDMA). The MDMA not only is an advocate for technological advancement with medical devices but also posts current issues that involve government taxes and other groups that may not be benefiting the industry, including "the group purchasing organization (GPO)".

A GPO is a group that can "realize savings and efficiencies by aggregating purchasing volume and using that leverage to negotiate discounts with manufacturers, distributors and other vendors" (Healthcare Supply Chain Association, 2011). Hospitals and other healthcare providers are increasingly relying on GPOs to help manage the complex system of purchasing and reduce the cost of goods and services (Hrehocik, 2010). The GPOs obtain large discounts based on the collective buying power of their members and then gain a profit by reselling the equipment to hospitals and clinics. Hu et al. (2011) suggest that many hospitals that contract with GPOs are following this practice. The percentage is between $96 \%$ and $98 \%$ in the United States. This practice is not all positive though as there are some ethical concerns. A report by the United States Government Accountability Office (2010) appears to agree that GPOs have collected unusually high administrative fees and limited themselves to a single supplier. This GPOs' practice, while possibly beneficial to the selected OEMs, may limit their customers' access to innovative technology. The Medical Device Manufacturing Association has been pushing for litigation that prevents GPOs from receiving kickbacks from suppliers through single sourcing, which can dampen technological improvements.

\subsection{Quality Regulations and Standards}

Quality is an important issue in a supply chain, especially for medical devices. While each country has its own regulations and standards of quality, several agencies around the world monitor regulations in place and the policies of medical devices. These agencies include the World Health Organization, the International Medical Device Forum, and the International Organization for Standardization (Lamph, 2012). The World Health Organization has medical device regulations for member countries (World Health Organization, 2014) including the United States that monitor the safety, performance, regulations, and standards of medical devices (World Health Organization, 2003). The Food and Drug Administration's regulations, ISO 9001:2008, ISO 13485:2003, good manufacturing practices, and clean room standards have been taken into account as the most pertinent regulations and standards for medical device manufacturers.

The regulations from the Food and Drug Administration (FDA) are key to manufacturing medical devices. The classification of the medical device, or devices, depends on which regulations would be applicable. According to FDA (2013), "manufacturers (both domestic and foreign) and initial distributors (importers) of medical devices must register their establishments with the FDA" and these manufacturers, along with most other companies associated with medical 
device manufacturing, such as distributing and sterilizing companies, must also list their medical devices.

The ISO has several certifications that are available for manufacturers and suppliers. The two most related to medical devices are ISO 9001:2008 and ISO 13485:2003. ISO 9001:2008, titled Quality Management System Requirements, focuses on customer requirements, standards of quality, and continuously increased customer satisfaction. It is a generic standard that most organizations and companies can be certified (International Organization for Standardization, 2012). This standard differs from ISO $13485: 2003$, as it is "to facilitate harmonized medical device regulatory requirements for quality management systems" (International Organization for Standardization, March 5, 2011). Even though the two standards have different requirements, and only ISO 9001:2008 can be used to get certified, both are useful for suppliers and manufacturers to obtain.

Good Manufacturing Practices are set through the FDA while Cleanroom Standards are a ten-part ISO. Good Manufacturing Practices, or now known as the Current Good Manufacturing process, has had an attached quality system regulation (U.S. Food and Drug Administration, 2011). This regulation, which is created for medical devices, is meant to be an overall quality system for all manufacturing firms. That includes audits, controls, and record keeping. This regulation is very similar to the ISO Cleanroom Standard. Despite the fact that the Cleanroom Standard does not have an exact definition to itself, it was made as a way to regulate the environment in which products are manufactured. The ISO site, for ISO 14644, had a list of ten parts to the standard, which monitors everything from surface particle cleanliness to air particle cleanliness.

These agencies and their regulations and standards are the foundation for manufacturing any medical equipment. These quality standards and regulations will be used to evaluate and select suppliers for parts and components. It is critical for suppliers to be held to high standards as the quality of their products is vital to a supply chain. Without recognizing, understanding, and implementing them, the medical device supply chain cannot be developed.

\subsection{Emerging Technologies}

As technology advances in its applications in healthcare so does every aspect of the supply chain for medical devices. Technology has been growing at an everincreasing rate. For example, Google Glass is being used as a tool for surgeons to have patient records or vitals right in front of them as they are performing surgery or as a training tool for students and for distance learning (Glauser, 2013). The Brain Machine Interface (BMI) is another area that is being researched as technology advances. This technology reads the brain waves and allows them to communicate wirelessly with other devices (Hirata et al., 2012). This technology will enable severely disabled people to have a life that has more freedom and is less dependent on caregivers. The third technology of a medical equipment supply chain is the micromachining that makes medical micromachined parts be smaller yet more precise. Micromachining is being relative to each
OEM has. According to Micro Engineering Solutions (2013), some may see it as machining down to the size of a micron, while others may just view it as introducing a level of precision previously impossible. Shanahan (2014) views micromachining as being, "micro in a very literal way, or 10-6, in other words, as one-millionth of a meter." Many medical devices require precision-made parts, like some medical components, which is why micromachining is a necessity (Shanahan, 2014).

However, the use of these technologies may be highly limited since it is subject to the governance of the US Health Insurance Portability and Accountability Act (HIPPA) or other laws/regulations that do not allow a third party to have access into patient information (Glauser, 2013). Glauser (2013) contends that technology is "exponentially leaping forward, at a pace that regulation is not keeping up with".

When developing a supply chain for a medical device with this type of advanced technology, the location of the available technology is another consideration. For example, in Washington State, only four companies do micromachining and three of them are located in the Metro Seattle area. Only one specializes in medical parts. Others are located between Oregon and California.

\subsection{Distribution and Global Markets}

The final part of a medical device supply chain is the distribution. Currently, the FDA has one minor regulation that monitors the distribution of medical devices. The big factor is "that companies must follow when exporting medical devices depend on whether or not their devices have been approved or cleared by the Food and Drug Administration" (U.S. Food and Drug Administration, 2014). The regulation states that if the device has already been cleared to be distributed throughout the United States, then it can be exported throughout the world if only permitted by the laws and regulations of importing countries in regard to medical devices as well.

Take two categories of medical devices, electromedical and surgical appliances and supplies as an example. There are six main countries that import these types of medical devices. For electromedical, the International Trade Administration's (2009) website (see Appendix A) shows that Japan imports the most followed by Germany, the Netherlands, Belgium, and Canada. These statistics are only up to the year 2008, but the dollar amount imported has been increasing every year. As for surgical appliances and supplies, the order of the countries is changed slightly, with one added and one dropped. The Netherlands imports the most followed by Japan, Canada, Ireland, and Germany along with the amount imported increasing every year (International Trade Administration, 2009) (see Appendix B). These documents show that the need for medical devices will continue to increase over time, meaning that a medical supply chain could be considered a safe investment for those companies involved.

While the focus of the information is on exporting, it is interesting to note that the United States imports a slightly higher dollar amount, just over $4 \%$, than it exports of products from both of these categories based on 2008 data from the International Trade Administration's (2009) website. When analyzing imports, the U.S., as of 2008, 
imports the largest amount from Ireland in both categories (see Appendices C and D). The importing of medical devices is also covered by the FDA. According to the FDA's website, "any foreign firm that imports medical devices or devices that emit radiation into the United States must comply with all applicable U.S. regulation before, during, and after importing into the U.S. or its territories." (U.S. Food and Drug Administration, 2014). In addition, the initial importer of the device must register with the FDA. All importers are also subject to Medical Device Reporting (MDR) (U.S. Food and Drug Administration, 2014). Devices that emit radiation are also subject to additional requirements. These requirements can be found under the Federal Food, Drug, and Cosmetic Act, Subchapter C - Electronic Product Radiation Control (U.S. Food and Drug Administration, 2014). These requirements include performance standards, labeling, and submission of radiation safety product reports.

\subsection{Maintenance, Repair, and Operations}

The maintenance, repair, and operations (MRO) of a supply chain refer to the maintaining and repairing of any device that is mechanical, plumbing, or electrical. Calibration is part of this; it is a type of preventative maintenance. When you calibrate a device that means you are comparing it with a known standard. This device is then recalibrated to specifications. Another part of this requirement is that the device is labeled. Each device should have a unique control number and a calibrated-until date on it (ISO, 2014). This is a necessary requirement for medical devices. Calibration and labeling are the first two requirements and the most important ones (ISO, 2014).

One proposal to help guide this would be to introduce a Medical Devices Maintenance System (MDMS). This system, once implemented, would eventually lead to better customer satisfaction (Al-Bashir et al., 2012). Maintenance systems have a tremendous impact on organizations' ability to meet their objectives. Over the last couple of decades, there have been huge improvements in all its areas including process, strategy, policy, procedure, and technology trying to introduce a high-quality technical service for medical devices operators (Al-Bashir et al., 2012). Since calibration is necessary to remain certified, a plan like this would be ideal to implement.

\section{A CASE STUDY OF MEDICAL DEVICE SUPPLY CHAIN}

A case is presented to show how the steps or components in the framework were applied to the supply chain development for two medical devices in the Washington State of the USA. The identity information of participating companies has been omitted or replaced with an acronym due to confidentiality consideration.

\subsection{Sample Medical Devices}

Two sections of medical devices were chosen to develop their supply chains based on their predicted future uses and their products' complex nature: electromedical and electrotherapeutic apparatus manufacturing and surgical appliances and supplies manufacturing. According to the United States Census Bureau's NAICS website
(2014), surgical and medical instrument manufacturing is comprised of "manufacturing electromedical and electrotherapeutic apparatus, such as magnetic resonance imaging equipment, medical ultrasound equipment, pacemakers, hearing aids, electrocardiographs, and electromedical endoscopic equipment." Of about one hundred products listed under this category, this study has a preference towards products of a more complex nature, leading to the choice of ultrasonic medical equipment manufacturing. Similarly, artificial limbs manufacturing was selected from the United States Census Bureau NAICS (2014) website for surgical appliance and supplies manufacturing.

Many ultrasound technologies are available with different applications, including abdominal imagining to scan internal organs, obstetric ultrasound imaging used during pregnancy, or even aorta ultrasound imaging to check for blood flow and clotting issues in the neck arteries (Atlantic Medical Imagining, 2014). Some therapeutic ultrasound systems allow for accelerating fractured bone repair in very careful doses (Warden et al., 2006).

Calibration is the biggest problem of the therapeutic ultrasound systems as no standard sets of dosage are specified for these systems. Robertson (2008) contends that having a system that is well calibrated is a must. Robertson (2008) further suggests that there is the expectation of receiving a machine fully calibrated to the correct standards. However, after multiple tests, the study found that manufacturers were not calibrating the devices properly. This finding reinforces the idea that an OEM needs to be manufacturing equipment to the standards and regulations of what is expected from the device, which is essential for being reliable in a supply chain.

Unlike ultrasound technologies and systems, artificial limbs, known as prosthetics, are developed much earlier. According to Thurston (2007), prosthetics have been developed not only out of necessity due to the loss of limbs but also for a person's psychological and spiritual wellbeing. Schaffalitzky et al. (2011) has conducted a focused study on the psychological impact of prosthetic limbs. The conclusion tends to be positive through the gaining of independence based on the individual and the type of prosthetic.

The military has been very influential towards the development of prosthetic limbs arose with the advances in technology developed in the two world wars (Thurston, 2007). In a study conducted by Gailey et al. (2010) who worked with Vietnam veterans to analyze lower limb prosthetics, it is found that the weight of the prosthetic is still a common problem making the limbs too troublesome to use and the use to cause users' pain. This finding indicates that the technology still has rooms for improvement and that, due to the current stigma associated with prosthetic limbs, OEMs need to help develop and customize prosthetic limbs, while furthering technologies, to improve customer satisfaction.

\subsection{Developing BOMs}

In order to develop the supply chains for these two devices, both the ultrasound machine and prosthetic ankle need to be broken down into components, sub-components, and raw materials to create their BOMs. From the 
literature, the BOMs of these items are found from two theses (Zeng, 2009; Cordeiro, 2006). The BOM for the prosthetic limb is for an ankle (Zeng, 2009). While both of these items are being evaluated in a hypothetical scenario, they are real, emerging technologies. The thesis for the wearable ultrasound was published in 2007. The wearable ultrasound device is different in a way that it does not tether a patient to a machine as the typical ultrasound device does. The technology behind both the ultrasound and prosthetic fields is changing rapidly. The difference between the ultrasound machine BOM and the prosthetic ankle BOM is that the ultrasound machine is made up of primarily electronic sub-components, with very little mechanical moving parts while the prosthetic ankle is purely mechanical, made of plastics and metals, but with no electronic parts.

To start the research on the ultrasound machine's BOM, an interview was conducted with Company ABC. Company $\mathrm{ABC}$ is a privately held ultrasound company located in a city within Washington State. The company provides ultrasounds and other tools that allow them to develop new algorithms for products in diagnostic, interventional, and therapeutic products.

Due to the ultrasound BOM being of a wearable prototype, additional research has been conducted on the external components. This includes the chassis, microphone, transducer, keyboard, monitor, and mouse. Each of these is from already-developed products. Between the researched BOMs and drawings, along with the interview with Company $\mathrm{ABC}$, the ultrasound machine has an overall materials list of over a hundred items.

The prototype prosthetic ankle BOM consists of parts that have been custom manufactured and those that have been bought from suppliers. Three raw materials make up the BOM, which includes Acrylonitrile Butadiene Styrene (ABS) plastic, aluminum, and steel. In order to develop a more comprehensive list of materials, additional research was carried out for a complete materials list. The results include materials that could possibly be used, such as an additional metal, plastic polymer laminates, thermoplastics, and other material that does not fall into the previously listed categories.

To assess which processes are necessary for the manufacturing of medical devices, an analysis of each medical device's materials is desired. The ultrasound machine is plastics and electronic components while the prosthetic is mainly plastics and metals. Ultrasound machines only have silk-screening, as many of these processes are outsourced to overseas. For the prosthetic ankle, the manufacturing processes include fabrication, milling, and machining of metal. Micromachining is included as well, though that is more a specialty and has potential uses for smaller prosthetics. Both medical devices include plastic injection molding and tooling. To determine whether or not it is possible to develop a supply chain within Washington State, a list of possible process manufacturers is developed both within the State and globally.

Though there are quite a few process manufacturers located within Washington State, this does not mean that they would work with or work on medical devices. The Washington State also contains one of the largest aerospace companies in the world, Boeing, and most metal process manufacturers as Boeing's suppliers. Industry certifications are different as well, being affiliated with aircraft. Manufacturers are spread out throughout the state. A major area that Washington appears to be lacking companies is in silk-screening and in micromachining. Through the additional supplier list with an anonymous company, it has been found that there are two silkscreening companies in Washington. Micromachining is a newer field and requires some of the latest technology, which is the major reason for the lack of companies.

\subsection{Identifying and Selecting Suppliers}

There are many process manufacturing companies available globally. Based on the previous research, the countries are selected based on whom the U.S. imported from the most for both the ultrasound machine NAICS category and the prosthetic NAICS category. The top five countries are selected from each and then consolidated to three countries overall, based on the number of medical devices the US imported from them. The countries researched are Ireland, Germany, and Japan. Each country has a large selection of each of the manufacturing processes.

When deciding on how far to go down the supply chain tiers for this project, it has been decided that there need to be two different approaches to investigating the tiers of the supply chain. For the ultrasound, the focus will be on tier 1 suppliers. This is due to the fact that there are not as many custom processes involved in creating most of the components. For the prosthetic ankle, the research into the tiers goes much deeper due to the fact that there are many processes involved in making these types of products. Instead of focusing on the first supplier tier, the research has focused on primarily supplier tier 1 and tier 2 , though there is some crossover into tier 3.

The supplier list has been developed only for the prosthetic ankle. The ultrasound machine includes mainly electronic components, which are not manufactured within the United States. For this reason, no supplier list has been developed for the ultrasound machine.

The prosthetic ankle is unique. About half of the components are mass produced parts, such as springs. The other half of the components is custom made. Therefore, the suppliers for both the components and the raw materials have to be identified and selected. At the same time, many of the mass-produced components are not manufactured within Washington State. Of those that are manufactured within the state, there is only one or two of each. The lack of supplier availability could possibly lead to issues when it comes to evaluating suppliers, such as with a supplier scorecard.

The supplier scorecard for medical device companies was developed after an interview and tour with two companies. The industry ultimately determines what goes on the scorecard and the ranking it receives. Through the interview process, it was determined that the scorecard ranking also depended on whether the device was used medically or for research. All things considered, the only difference was in price. According to an interview with Company $\mathrm{ABC}$, the price is at the bottom due to the fact that when it comes to funding for research projects, it is 
much easier for the researchers to get grant money to purchase the item than it is to get funding to repair something. They have to build something that is going to last longer without as much repair or maintenance requirement. Being that it is the medical field, either way, a medical device is used, quality ranked as the top requirement. The main focus of this project was for medical purposes. The factors on the scorecard are quality, location, price, ISO certifications, and reputation. All factors ultimately support quality as being the main ranking factor in supplier selection.

In Washington State, six OEMs have been identified to manufacture ultrasounds while only one is identified for prosthetics. This information is identified trying to answer the question on whether or not Washington State was a cluster. While this may not be an exhaustive list, it is representative of the ratio. There is essentially a 6 to 1 ratio of OEMs. Harvard Business School, under the direction of Michael Porter, has started a cluster mapping project that shows cluster mapping by region using the county business patterns (CBP) from the government census website. According to this research (Porter, 2012), Washington State is a cluster for electromedical and electrotherapeutic apparatus (ultrasounds), but not surgical appliance and supplies (prosthetics).

\section{RESULTS, CONCLUSIONS, DISCUSSIONS, AND FUTURE STUDIES}

This study proposed an initial framework for developing medical device supply chains and presented a case that used the framework to develop supply chains for two medical devices. The result of this study suggests that it is impossible to develop a supply chain with all of its suppliers or manufacturing companies solely located within Washington State. Currently, the state is lacking component and raw material manufacturers. The State is also not considered a cluster for prosthetic ankles. This medical device has only one OEM throughout the entire Washington State and a limited number within the United States. The possible reasons for this could be due to the nature of the device itself. A prosthetic ankle is a custommade device. A prosthetic will only be covered by insurance once every five years by most insurance companies. It is not a cheap medical device either. The overall cost, based on the original BOM (Zeng, 2009), is a little over seven thousand dollars. These two factors are most likely the reason why the prosthetic is not a cluster within Washington State. There is hope for the ultrasound machine. There are quite a few OEMs located within the State, and the ultrasound machine is a cluster zone. With further supplier development, the ultrasound machine could possibly have its own supply chain within Washington State.

Future studies could validate the framework with additional medical devices. The validation could focus on the entire supply chain or a segment of the supply chain. The results will help either offer insights about the applicability of the framework or improve the framework to make it more useful in guiding the development of the initiatives for medical device supply chains.

\section{ACKNOWLEDGEMENTS}

The first author acknowledges Alexandrea Berry and Jennifer Anderson for their assistance in collecting and summarizing information related to the case studies.

\section{REFERENCES}

Al-Bashir, A., Al-Rawashdeh, M., Al-Hadithi, R., Al-Ghandoor, A., and Barghash, M. (2012). Building Medical Devices Maintenance System through Quality Function Deployment. Jordan Journal of Mechanical \& Industrial Engineering, 6(1), pp. 25-36.

Ali, S.M. and Nakade, K. (2015). A Mathematical Optimization Approach to Supply Chain Disruptions Management Considering Disruptions to Suppliers and Distribution Centers. Operations and Supply Chain Management: An International Journal, 8(2), pp. 57-66.

Atlantic Medical Imagining (2014). Types of Ultrasounds. Retrieved from: http://www.atlanticmedicalimaging.com/pages/types-ofultrasounds

Castiaux, E. (2010). An Introduction to Cold Chain Management. Journal of GXP Compliance, 14(4), pp. 19-22.

Castiaux, E. (2011). Introduction to Cold Chain Management Part II. Journal of GXP Compliance, 15(1), pp. 49-53.

Cheng-Min, C., and Bor-Wen, C. (2012). Factors Influencing the Future Relationship of Hospital Procurement staff with Medical Device Suppliers. Social Behavior \& Personality: An International Journal, 40(6), pp. 945-958.

Cheng-Min, C., Cheng-Tao, Y., Bor-Wen, C., and Pen-Chen, C. (2013). Trust and Commitment in Relationships among Medical Equipment Suppliers: Transaction Cost and Social Exchange Theories. Social Behavior \& Personality: An International Journal, 41(7), pp. 1057-1069.

Cordeiro, P. (2006). Design of a Wearable Ultrasound System. Worchester Polytechnic Institute. Retrieved From: http://www.wpi.edu/Pubs/ETD/Available/etd-081406144053/unrestricted/MSThesis.pdf

Emergo Group (2007). Are you considered a Medical Device Manufacturer? Retrieved from: http://www.emergogroup.com/resources/articles/are-youa-medical-device-manufacturer

European Commission (2007). Interpretation of the Medical Device Directives in Relation to Medical Device own Brand Labellers. Interpretive Document of the Commission's Services. Retrieved from: http://ec.europa.eu/health/medical-devices/files/guidestds-directives/interpretative_fiche_obl_en.pdf.

Formby, S.K., and Malhotra, M.K. (2016). Self-inflicted Supply Risk: An Empirical Investigation. Operations and Supply Chain Management: An International Journal, 9(3), pp. 161-171.

Gailey, R., McFarland, L.V., Cooper, R.A., Czerniecki, J., Gambel, J.M., Hubbard, S., and Reiber, G.E. (2010). Unilateral lower-limb loss: Prosthetic Device Use and Functional Outcomes in Service Members from Vietnam war and OIF/OEF conflicts. Journal of Rehabilitation Research \& Development, 47(4), pp. 317-331.

Glauser, W. (2013). Doctors among early adopters of Google Glass. CMAJ: Canadian Medical Association Journal, 185(16), pp. 109-4607.

Grocott, P., Weir, H., and Ram, M.B. (2007). A model of user engagement in medical device development. International Journal of Health Care Quality Assurance, 20(6,), pp. 484493.

Hasani, A., Zegordi, S.H. and Nikbakhsh, E. (2015). Robust closed-loop global supply chain network design under uncertainty: the case of the medical device industry. 
International Journal of Production Research, 53(5), pp. 1596-1624.

Healthcare Supply Chain Association (2011). HSCA: Healthcare Supply Chain Association. Welcome! Retrieved from: http://www.supplychainassociation.org/

Hirata, M., Matsushita, K., Yanagisawa, T., Goto, T., Morris, S., Yokoi, H., and Yoshimine, T. (2012). Motor Restoration Based on the Brain-Machine Interface Using Brain Surface Electrodes: Real-Time Robot Control and a Fully Implantable Wireless System. Advanced Robotics, 26(3/4), pp. 399-408.

Hrehocik, M. (2010). Group Purchasing Organizations. LongTerm Living, 59(7), pp. 23-24.

Hu, Q., Schwarz, L., and Uhan, N. (2011). The Impact of Group Purchasing Organizations on 2 Healthcare-Product Supply Chains. Retrieved from: http://www.krannert.purdue.edu/faculty/lee/Papers/Submit ted $\% 20$ for $\% 20$ Publication/The $\% 20$ Impact $\% 20$ of $\% 20 \mathrm{Grou}$ p\%20Purchasing\%20Organizations...Supply\%20Chains.p df

International Organization for Standardization (2012). ISO 9001:2008--Quality Management Systems - Requirements. Retrieved

From: http://www.iso.org/iso/home/store/catalogue_tc/catalogue _detail.htm?csnumber $=46486$

International Organization for Standardization (2011). ISO 13485:2003 - Medical Devices - Quality Management systems - Requirements for Regulatory Purposes. Retrieved From: http://www.iso.org/iso/home/store/catalogue_tc/catalogue detail.htm?csnumber $=36786$

International Organization for Standardization (n.d.). Search: ISO 14644. Retrieved from: http://www.iso.org/iso/home/search.htm?qt=14644\&sort=r el\&type $=$ simple \&published $=$ on

International Trade Administration (2009). Electromedical: FAS Value by FAS Value for All Countries. U.S. Domestic Imports. Retrieved From: http://ita.doc.gov/td/health/imp08334510.html

International Trade Administration (2009). Electromedical: FAS Value by FAS Value for All Countries. U.S. Domestic Exports. Retrieved From: http://ita.doc.gov/td/health/exp08334510.html

International Trade Administration (2009). Surgical Appliances and Supplies: FAS Value by FAS Value for All Countries. U.S. Domestic Exports. Retrieved From: http://ita.doc.gov/td/health/exp08339113.html

International Trade Administration (2009). Surgical Appliances and Supplies: FAS Value by FAS Value for All Countries. U.S. Domestic Imports. Retrieved From: http://ita.doc.gov/td/health/imp08339113.html

Kumar, S., DeGroot, R.A., and Choe, D. (2008). Rx for smart hospital purchasing decisions: The impact of package design within US hospital supply chain. International Journal of Physical Distribution \& Logistics Management, 38(8), pp. 601-615.

Mather, H.F. (1986). Design, Bills of Materials, and ForecastingThe Inseparable Threesome. Production \& Inventory Management. 27(1), pp. 90-107.

Micro Engineering Solutions (2013). Micro Machining. Retrieved http://www.microengineeringsolutions.com/blog/micromachining-2/

Lamph, S. (2012). Regulation of Medical Devices Outside the European Union. Journal of the Royal Society of Medicine (Supplement), 105(Supp 1), pp.12-21.

Liao, K., Bayazit, O. and Wang, F. (2014). Building a Natural Disaster Risk Index for Supply Chain Operations.
International Journal of Information Systems and Supply Chain Management, 7(4), pp.20-30.

Pishvaee, M.S., Razmi, J., and Torabi, S.A. (2014). An accelerated Benders decomposition algorithm for sustainable supply chain network design under uncertainty: A case study of medical needle and syringe supply chain. Transportation Research Part E, 67, pp. 14-38.

Porter, M. (2012). U.S. Cluster Mapping. U.S. Cluster Mapping Website. Retrieved May 6, 2014, from: http//clustermapping.us/home/.

Ratick, S., Meacham, B., and Aoyama, Y. (2008). Locating Backup Facilities to Enhance Supply Chain Disaster Resilience. Growth \& Change, 39(4), pp. 642-666.

Reid, R.D. and Sanders, N.R. (2002). Operations Management. John Wiley \& Sons. pp. 457-458.

Robertson, V.J. (2008). Invited Commentary. Physical Therapy, 88(1), pp. 58-61.

Schaffalitzky, E., Gallagher, P., Maclachaln, M., and Ryall, N. (2011). Understanding the benefits of prosthetic prescription: exploring the experiences of practitioners and lower limb prosthetic users. Disability \& Rehabilitation, $33(15 / 16)$, pp. 1314-1323.

Shanahan, J. (2014). Trends in Micro Machining Technologies. Makino. Retrieved from http://www.makino.com/about/news/trends-in-micromachining-technologies/315/

Thurston, A.J. (2007). Pare and Prosthetics: The Early History of Artificial Limbs. ANZ Journal of Surgery, 77(12), pp. 11141119.

U.S. Food and Drug Administration (2011). Medical Devices: Quality System (QS) Regulation/Medical Device Good Manufacturing Practices. Retrieved from: http://www.fda.gov/MedicalDevices/DeviceRegulationand Guidance/PostmarketRequirements/QualitySystemsRegula tions/

U.S. Food and Drug Administration (2014). Medical Devices: Exporting Medical Devices. Retrieved from: http://www.fda.gov/medicaldevices/deviceregulationandg uidance/importingandexportingdevices/ucm050521.htm

U.S. Food and Drug Administration (2013). Medical Devices: Overview of Device Regulation. Retrieved from: http://www.fda.gov/MedicalDevices/DeviceRegulationand Guidance/overview/

Unger, S. and Landis, A. (2016). Assessing the environmental, human health, and economic impacts of reprocessed medical devices in a Phoenix hospital's supply chain. Journal of Cleaner Production, 112(3), pp. 1995-2003.

United States Census Bureau (2014). 2012 NAICS Definition. North American Classification Industry Classification System. bin/sssd/naics/naicsrch https://www.census.gov/cgi-

United States Government Accountability Office (2010). Group Purchasing Organization: Services Provided to Customers and Initiatives Regarding Their Business Practices. Retrieved from: http://www.gao.gov/new.items/d10738.pdf.

Wang, M., Jie, F., and Abareshi, A. (2014). The Measurement Model of Supply Chain Uncertainty and Risk in the Australian Courier Industry. Operations and Supply Chain Management: An International Journal. 7(3), pp. 89-96.

Warden, S.J., Fuchs, R.K., Kessler, C.G., Avin, K.G., Cardinal, R.E., and Stewart, R.L. (2006). Ultrasound Produced by a Conventional Therapeutic Ultrasound Unit Accelerates Fracture Repair. Physical Therapy, 86(8), pp. 1118-1127.

Wells, P.T., Liang, H., and Young, T.P. (2011). Ultrasonic imaging technologies in perspective. Journal of Medical Engineering \& Technology, 35(6/7), pp. 289-299.

World Health Organization (2003). Medical Devices Regulations: Global Overview and Guiding Principles. 
Retrieved from: http://whqlibdoc.who.int/publications/2003/9241546182.p df?ua=1

World Health Organization (2014). Medical Devices Regulations. Retrieved from: http://www.who.int/medical_devices/safety/en/

Xie, Y., Breen, L., Cherrett, T., Zheng, D., and Allen, C.J. (2016). An exploratory study of reverse exchange systems used for medical devices in the UK National Health Service (NHS). Supply Chain Management: An International Journal, 21(2), pp. 194-215.
Zarrinpoor, N., Fallahnezhad, M.S., and Pishvaee, M.S. (2018). The design of a reliable and robust hierarchical health service network using an accelerated Benders decomposition algorithm. European Journal of Operational Research, 265, pp. 1013-1032.

Zeng, Y. (2009). Design and Testing of a Passive Prosthetic Ankle with Mechanical Performance Similar to That of a Natural Ankle. Marquette University. http://epublications.marquette.edu/cgi/viewcontent.cgi?arti cle $=1187 \&$ context $=$ theses_open.

\section{APPENDIX A}

\begin{tabular}{|c|c|c|c|c|c|c|c|}
\hline & \multicolumn{6}{|c|}{ U.S. Domestic Exports } & \\
\hline & 2003 & 2004 & 2005 & 2006 & 2007 & 2008 & Percent Change \\
\hline Country & & & $\ln 1,000$ & Dollars & & & $2007-2008$ \\
\hline Japan & 612,563 & 676,273 & 815,343 & 915,222 & 819,680 & 840,333 & $2.50 \%$ \\
\hline Germany & 772,632 & 567,920 & 631,734 & 728,091 & 741,197 & 811,243 & $9.50 \%$ \\
\hline Netherlands & 393,368 & 448,042 & 498,623 & 632,617 & 642,456 & 724,542 & $12.80 \%$ \\
\hline Belgium & 100,187 & 126,833 & 192,563 & 252,303 & 416,629 & 473,387 & $13.60 \%$ \\
\hline Canada & 265,241 & 285,227 & 324,590 & 363,577 & 394,048 & 416,860 & $5.80 \%$ \\
\hline China & 158,104 & 185,831 & 232,608 & 220,833 & 323,320 & 413,541 & $27.90 \%$ \\
\hline Sweden & 163,600 & 188,001 & 226,056 & 312,555 & 378,932 & 379,070 & $0.00 \%$ \\
\hline $\begin{array}{l}\text { United } \\
\text { Kingdom }\end{array}$ & 188,318 & 256,093 & 311,001 & 330,520 & 343,158 & 347,012 & $1.10 \%$ \\
\hline Mexico & 129,697 & 119,812 & 134,304 & 139,668 & 260,729 & 339,810 & $30.30 \%$ \\
\hline France & 189,680 & 228,787 & 228,827 & 246,062 & 280,255 & 324,112 & $15.60 \%$ \\
\hline Australia & 161,156 & 183,142 & 224,645 & 264,158 & 284,065 & 285,510 & $0.50 \%$ \\
\hline Brazil & 82,086 & 94,764 & 115,423 & 158,038 & 171,946 & 222,686 & $29.50 \%$ \\
\hline Italy & 118,033 & 143,885 & 164,976 & 181,028 & 166,828 & 184,287 & $10.50 \%$ \\
\hline Korea & 119,532 & 115,215 & 139,302 & 156,725 & 193,288 & 176,559 & $-8.70 \%$ \\
\hline Spain & 73,888 & 89,312 & 101,921 & 125,174 & 150,970 & 161,740 & $7.10 \%$ \\
\hline Subtotal : 3 & $3,528,084$ & $3,709,136$ & $4,341,915$ & $5,026,572$ & $5,567,500$ & $6,100,691$ & $9.60 \%$ \\
\hline All Other: & 876,863 & $1,052,635$ & $1,228,107$ & $1,412,704$ & $1,639,378$ & $1,969,729$ & $20.20 \%$ \\
\hline Total 4 & $4,404,947$ & $4,761,771$ & $5,570,023$ & $6,439,276$ & $7,206,878$ & $8,070,420$ & $12.00 \%$ \\
\hline
\end{tabular}




\section{APPENDIX B}

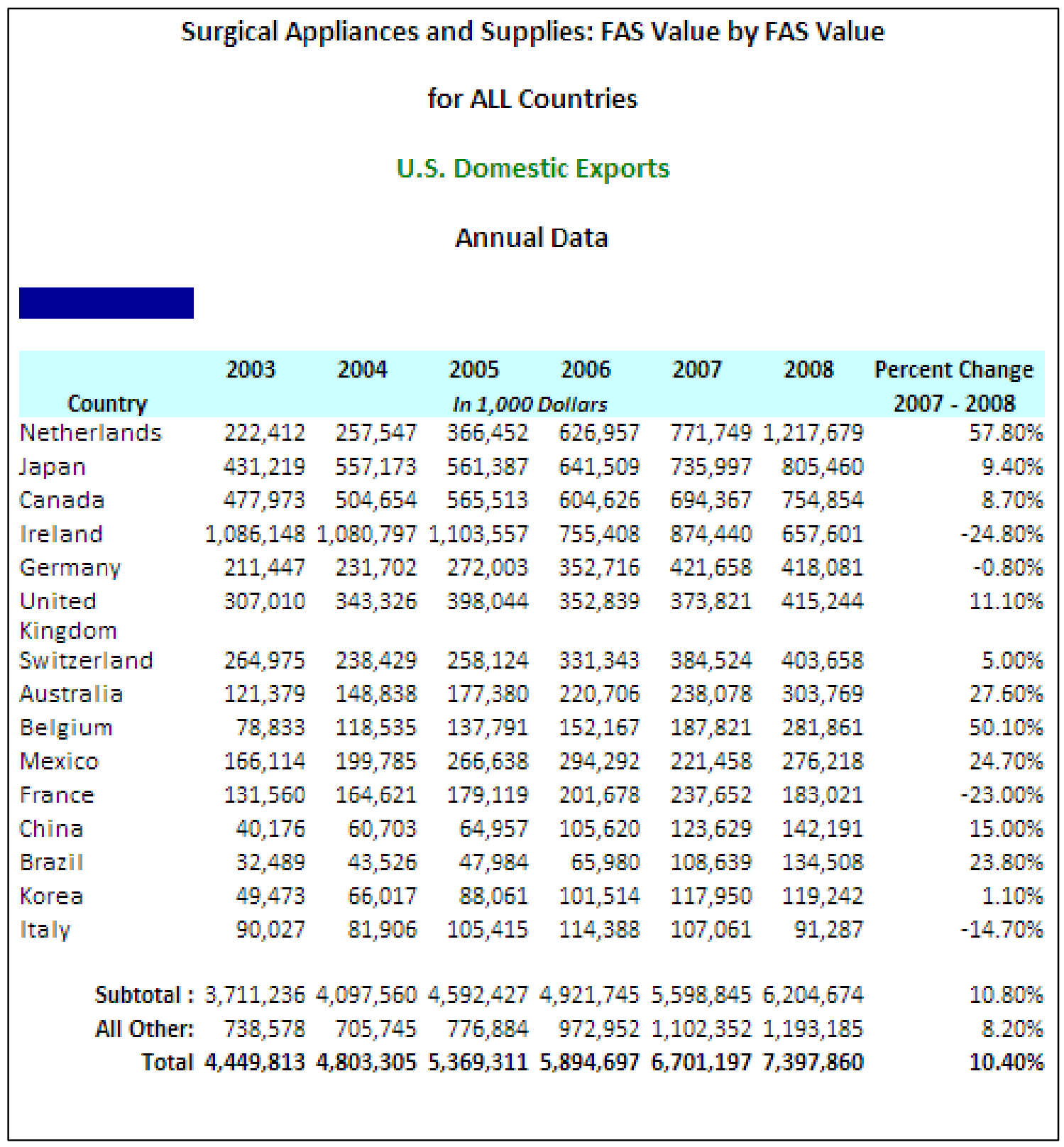




\section{APPENDIX C}

\begin{tabular}{|c|c|c|c|c|c|c|c|}
\hline & Electro & omedical: & $\begin{array}{l}\text { Customs } \\
\text { for ALL C } \\
\text { nports for }\end{array}$ & ountries & Customs & Value & \\
\hline & 2003 & 2004 & 2005 & 2006 & 2007 & 2008 & Percent Change \\
\hline Country & & & $\ln 1,000$ & Dollars & & & $2007-2008$ \\
\hline Ireland & $1,323,344$ & $1,368,403$ & $1,350,059$ & 939,330 & 919,136 & $1,393,155$ & $51.60 \%$ \\
\hline Germany & 806,466 & 873,231 & $1,005,643$ & $1,087,992$ & $1,239,471$ & $1,226,197$ & $-1.10 \%$ \\
\hline Japan & 695,262 & 766,739 & 824,826 & 805,052 & 834,996 & 878,569 & $5.20 \%$ \\
\hline Mexico & 445,831 & 455,465 & 453,599 & 531,508 & 685,227 & 766,200 & $11.80 \%$ \\
\hline China & 72,599 & 91,044 & 126,664 & 229,791 & 352,143 & 440,252 & $25.00 \%$ \\
\hline Singapore & 313,430 & 336,451 & 353,280 & 315,647 & 487,527 & 308,429 & $-36.70 \%$ \\
\hline Denmark & 164,706 & 205,688 & 238,309 & 248,072 & 257,667 & 260,038 & $0.90 \%$ \\
\hline Israel & 127,091 & 169,821 & 193,842 & 233,838 & 280,737 & 246,129 & $-12.30 \%$ \\
\hline Netherlands & 144,756 & 138,255 & 156,073 & 158,005 & 158,779 & 189,677 & $19.50 \%$ \\
\hline Canada & 226,612 & 259,303 & 239,987 & 283,329 & 210,093 & 185,569 & $-11.70 \%$ \\
\hline Switzerland & 238,570 & 168,175 & 186,952 & 214,037 & 206,553 & 184,332 & $-10.80 \%$ \\
\hline Australia & 56,390 & 56,885 & 73,955 & 101,058 & 109,278 & 134,349 & $22.90 \%$ \\
\hline Korea & 47,253 & 61,171 & 78,677 & 123,917 & 142,811 & 129,322 & $-9.40 \%$ \\
\hline United Kingdom & 113,229 & 123,319 & 145,397 & 143,671 & 122,508 & 109,631 & $-10.50 \%$ \\
\hline Costa Rica & 21,934 & 31,430 & 52,136 & 79,686 & 96,282 & 92,092 & $-4.40 \%$ \\
\hline Subtotal: & $4,797,472$ & $5,105,379$ & $5,479,399$ & $5,494,934$ & $6,103,210$ & $6,543,941$ & $7.20 \%$ \\
\hline All Other: & 509,009 & 508,599 & 594,779 & 565,928 & 624,501 & 672,565 & $7.70 \%$ \\
\hline Total & $5,306,481$ & $5,613,978$ & $6,074,178$ & $6,060,862$ & $6,727,711$ & $7,216,506$ & $7.30 \%$ \\
\hline
\end{tabular}




\section{APPENDIX D}

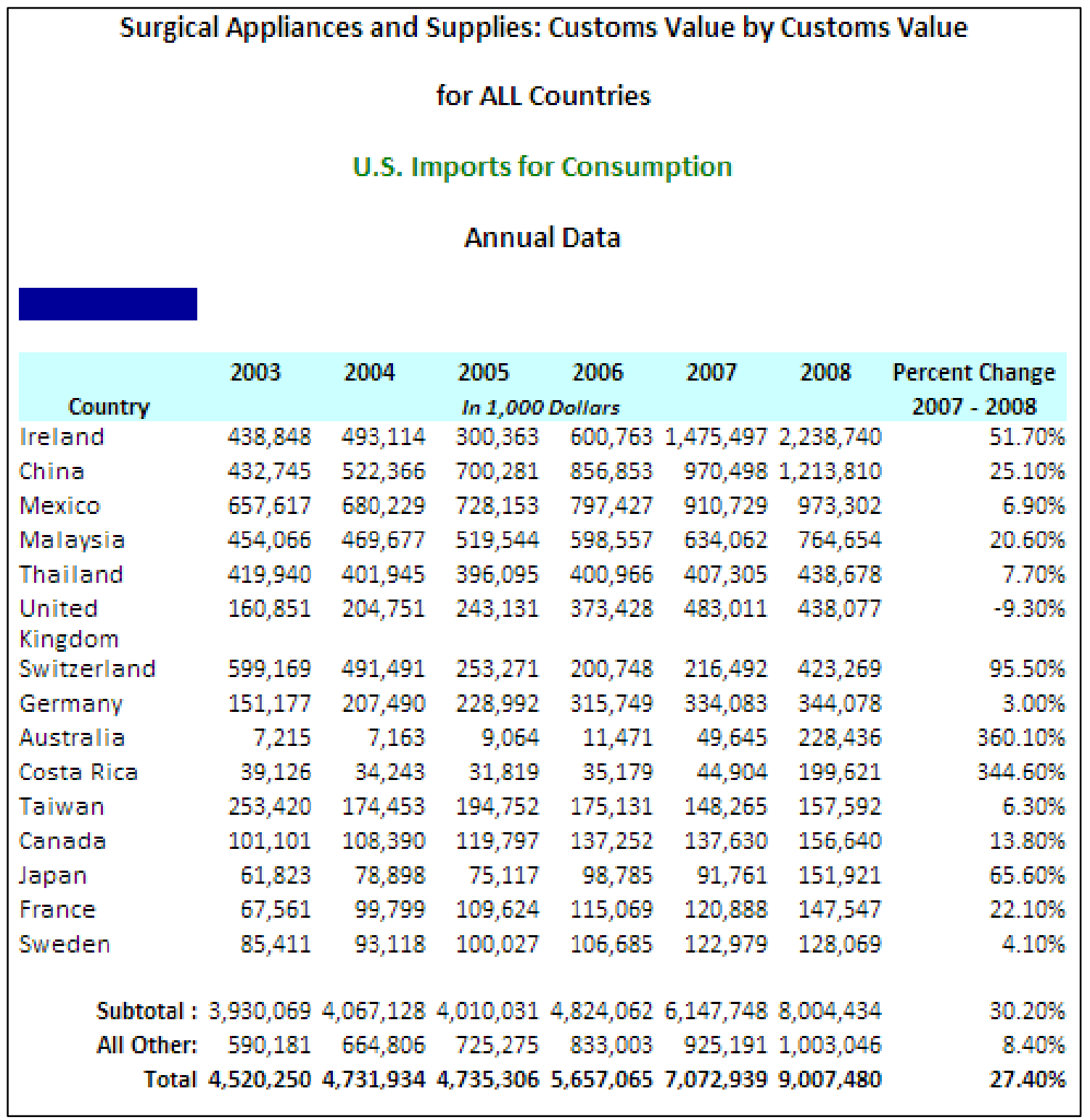

Kun Liao is Professor of Supply Chain Management in the College of Business, Central Washington University. He received his Ph.D. in Manufacturing Management and Engineering from The University of Toledo. His research has appeared in International Journal of Production Economics, Journal of Manufacturing Technology Management, Information Systems Management, and others. He is currently interested in supply chain strategy and purchasing and supplier management.

Xiaodong Deng is a Professor of Management Information Systems at Oakland University. He received his Ph.D. in Manufacturing Management and Engineering from The University of Toledo. His research has appeared in Journal of Management Information Systems, Decision Sciences, Information and Management, Communications of the Association for Information Systems, and International Journal of Production Economics. His research interests are in post-implementation information technology learning, information technology acceptance and diffusion, and supply chain management.

Yan Wang has been working in the finance field with leading US companies such as T-Mobile and Starbucks. She received her master's degree from George Washington University. She published article in International Journal of Technology, Policy and Management. Her research interest is on finance issues of supply chain management and supply chain strategy.

Ozden Bayazit is Professor of Supply Chain Management in the College of Business, Central Washington University. Her work has appeared in International Journal of Production Economics, Benchmarking: An International Journal, International Journal of Business Innovation and Research, Journal of Systems Science and Systems Engineering, Journal of Manufacturing Technology Management, and others. She is currently interested in researching supply chain risk management and sustainable supply chains. 